\title{
Monster at the Foot of the Bed: Surviving the Challenge of Marketplace Forces on Higher Education
}

\author{
Raoul A. Arreola \\ University of Tennessee Health Science Center
}

The impact of technology on society has caused a paradigm shift in the basic support for higher education. Where higher education was traditionally supported as a function of government, the knowledge explosion and global economy resulting from the impact of computer and other technologies is moving the underlying support of higher education to the marketplace. There is evidence that traditional academic strategies and practices that were successful under the old paradigm may no longer be working. Twelve suggestions are offered for revolutionary changes that the academy must make in order to survive, even thrive, in the new paradigm.

\section{Introduction}

At the 2004 annual POD (Professional and Organizational Development Network in Higher Education) meeting held in Montreal, I had the privilege and great pleasure of participating in a session dealing with the question of whether students were customers of higher education. The session, structured as a mock trial before a panel of "supreme court justices," gave participants the opportunity to testify and argue for one side or the other. I was fortunate to be selected to serve as one of the judges. The deliberations among the judges and the participants led to a tentative conclusion that society as a 
whole was the customer of higher education, and, as members of society, students were part of that customer base.

What was especially fascinating, however, was the aspect of the discussion that considered higher education as a part of the larger economic engine of American society. This perspective on higher education is one that has been of particular interest to me during the last few years since my university, like many others across the nation, continues to experience annual declines in its state budget. When one examines higher education as a social enterprise within the larger context of the American culture and economy of the 21st century, it is clear that the academy is experiencing a significant shift in the paradigm within which it must operate.

\section{Monster Under the Bed}

In 1994, two businessmen, Stan Davis and Jim Botkin, authored a particularly prescient book entitled The Monster Under the Bed: How Business Is Mastering the Opportunity of Knowledge for Profit. The "monster" under the bed was seen as the paradigm shift being brought about by the impact of technology on all segments of American society-especially education. While chronicling the various social, political, economic, and religious forces that impact education, the authors make one major point that is of particular interest here, namely, that education, as a social enterprise, has historically been supported by different segments of society and that a shift in that support is once again occurring-perhaps to the academy's detriment.

Through successive periods of history, different institutions have borne the major responsibility for education. Changes in education take a very long time to evolve. They are a consequence of greater transformations, often social, political, economic, or religious, and therefore are always a few steps behind the demands of the society they are designed to serve. But today schools are more than a few steps behind, and many feel they are on the wrong path altogether. (Davis \& Botkin, 1994, p. 23)

Davis and Botkin point out that from an historical perspective, organized educational efforts originated as a function of the church. Later, especially in America, the responsibility for supporting education moved to the government (when an educated populace was seen as necessary for the successful functioning of a free, democratic society). Now, with the ubiquity of the computer, the Internet, and the resultant knowledge explosion and global economy, the underlying support for education is moving from the government to 
the marketplace. The social paradigm under which higher education has successfully functioned, and been supported for generations, is undergoing a significant change. In short, I believe the monster has moved out from under the bed, yanked off the covers, and is gnawing at the academy's vitals.

\section{The Monster}

The term paradigm shift was defined and popularized by Thomas Kuhn (1970) in his seminal work The Structure of Scientific Revolution. Kuhn defined a paradigm shift as a "series of peaceful interludes punctuated by intellectually violent revolutions... [where] one conceptual world view is replaced by another" (p. 10). The literature on paradigm shifts suggests that an enterprise often must lose a considerable amount of its resources before it realizes that the shift has occurred. In addition, as an enterprise begins to feel the pain of losing resources, it frequently increases those activities that brought it success in the past. By the very fact of the shift in paradigm, however, those activities are precisely the ones most likely to contribute to the enterprise's decline and demise under the new paradigm.

There is little doubt that higher education as a social enterprise is experiencing a loss of resources. During the 2004 calendar year, the Chronicle of Higher Education published numerous accounts of state budget cuts to higher education. In some instances colleges merged together to remain economically viable; in others, colleges were reported to simply have declared bankruptcy and closed down. More recently, colleges have been encouraged to privatize so as to tap into commercial resources (Mangan, 2005; Schmidt, 2003). Predictably, the higher education enterprise has doubled and redoubled those activities that, under the old paradigm, brought great success, namely, intensifying development (fundraising) efforts and pushing faculty to bring in more research grant money.

Although the major goal of the U.S. universities is the advancement and dissemination of knowledge, universities also need funding to support their activities. A university must seek revenue from a variety of sources and more and more, faculty members are encouraged to generate income. (Howard Hughes Medical Institute, 2004, p. 27)

The response of intensifying development programs clearly indicates that colleges and universities have internalized their status as professional begging institutions. However, the new market-driven paradigm is moving the money elsewhere-witness the recent government evisceration of the 
Fund for the Improvement of Post Secondary Education (FIPSE), and the changes in the federal formula that reduces student aid (Burd, 2005; Field, 2005; Selingo, 2003).

What is going on here? Just as the invention of the printing press created a paradigm shift that precipitated the move of support for higher education from the church to government, the advent of the Internet, the global econo$m y$, and the emergence of knowledge businesses (i.e., corporate universities, commercial online universities, etc.) is shifting the support base of higher education from the government to the marketplace (maybe students are the customers). This means that colleges and universities must compete not only with one another, but also with other, non-educational societal interests and priorities. In short, the rules under which higher education has successfully operated for so long have changed and, if the academy is to continue to thrive-indeed if it is to survive as we have known it-it must adapt to the new rules.

I don't presume to be an expert on the paradigm shift phenomenon, the complexity of the full impact of computer technology on society, or even on all the operational aspects of colleges and universities. However, as an active participant in the higher education enterprise for the last 35 years, I would like to offer a few observations relative to the pains or losses the Academy is experiencing under the new paradigm-a look into the jaws of the monster, as it were.

\section{The Jaws of the Monster}

In August 2000, the Council for Higher Education Accreditation, the umbrella organization for higher education accrediting agencies, issued an occasional paper prepared by the National Center for Higher Education Management Systems titled The Competency Standards Project: Another Approach to Accreditation Review. This paper was one of those "intellectually violent events" Kuhn (1970) described that serve to define a paradigm shift. At its most fundamental level, this report proposed shifting the accreditation process from one of evaluating processes to one of evaluating outcomes. The question asked of higher education was about to change from "What resources do you have and what are you doing with them?" to "How much have your students learned and what can they actually do as a result of the experience you gave them?" Institutions that have just completed or are currently undergoing an accreditation review are intensely familiar with the pain and cost resulting from this element of the paradigm shift. The shift was so enormous it cannot 
be overstated-it essentially redefined what society specifically expects of the professoriate-it rewrote the social contract between the academy and society, between the professor and the student.

Under the old paradigm, the academy was expected to serve a "filtering" function. A personal case in point: on my first day as a freshman at Arizona State University in 1961, I and all the other freshmen were brought into a large auditorium to listen to a speech from the dean. The speech ended with the dean saying, "Look to your left, look to your right, one of you won't be here next semester." I, like everyone else at the time, took this to be an expression of the quality and rigor of the institution and felt a sense of pride and confidence, sure that I would be one of the survivors.

What the dean was conveying to us was the essence of the contract the academy had with society: It was expected to sort students into various levels-from the ablest to the least able. From this paradigm comes the tradition of grading on the curve. Each faculty member, in each course, each year, would flunk a certain percentage of students, so that by the senior year, the students that were left were the "survivors." That is, they constituted that segment of the population that could learn no matter what obstacles and challenges were put before them. A college graduate, then, was known by society to be the best and the brightest that could be produced. College graduates were valued and, mostly, paid appropriately.

This type of filtering contract even extended down into high school where students were sorted, on the basis of standardized tests, into one of three tracks: the college preparatory track, the general education track, or the vocational education track (students were responsible for their own selfesteem in those days). The college prep students were those destined to go to college (although not necessarily survive); the general education track students would go to work upon graduation (they could go to college if they wanted but were not expected to survive); and the vocational education track students became electricians, mechanics, plumbers, secretaries, and so on. It was a matter of common knowledge, as well as some research, that college graduates would make a lot more money during their lifetime than those that did not finish or never went to college. However, a sure sign that the paradigm was beginning to shift was when more and more millionaires started emerging from the vocational education track. Of course, Bill Gates, the richest man in the world (as of this writing), is a college dropout.

The new paradigm moves the academy from a filtering function to, ironically, a true instructional/teaching function. That is, instead of sorting the bright from the not-so-bright, the talented from the not-so-talented, the persistent from the not-so-persistent, society is now demanding that the academy 
accept virtually anyone who comes in the door and take them from whatever level of ignorance and ability they possess upon entrance up to some specified level of employable competence. Moreover, society is expecting the academy to do this in a timely and cost-effective manner (evidence of the corporate justin-time-training influence).

Under the old paradigm, scholarship was the sine qua non of the professoriate's activities and responsibilities. Within this paradigm, research was the most highly valued activity. However, as the new paradigm began to take hold, the demand for accountability in teaching grew. Valuing teaching under the traditions and beliefs of the old paradigm proved to be extraordinarily difficult. Even given the Herculean intellectual and philosophical efforts of Ernest Boyer (1990) to raise the value of teaching up to that of research by defining scholarship as including teaching, research has remained the most valued professional activity among the professoriate because it can generate money. Research has been highly valued because, under the old paradigm, it produced both increased funds for the institution and increased prestige for the institution and the scholar. In short, it made both the institution and the scholar appear worthy of societal support.

In Boyer's work, under the old paradigm, the presumption is made that teaching is an extension of research (scholarship). Under the new paradigm, teaching is seen as a separate, high-level profession in and of itself, requiring not only the content expertise of the traditional scholar, but expertise in instructional design, instructional delivery (including the use of computer and communication technology), and instructional assessment (Arreola, Aleamoni, \& Theall, 2001; Arreola, Theall, \& Aleamoni, 2003). Those institutions in the knowledge business, such as Phoenix University and the various corporate universities, recognize this new paradigm and use teams of individuals with these different areas of expertise to produce and deliver their instructional experiences. However, as the professoriate persists in those activities and traditions that made the academy successful under the old paradigm, certain losses are beginning to be felt across higher education. The academy is beginning to feel the monster's fangs.

\section{The Monster's Fangs}

One of the more visible signs of the effect of the paradigm shift is what might be called the Rodney Dangerfield Effect. That is, the professoriate, traditionally treated as elite members of society, has lost much of the respect it enjoyed 
in years past. Part of the reason for this, I believe, is the easy access to information provided by technology, especially the Internet.

When information was difficult to come by, the college professor, as a guardian and producer of knowledge, as a pedagogical priest, was valued and perhaps even revered. Under the old paradigm the teacher/scholar was the center of the teaching/learning universe. The teacher/scholar conducted the research to discover or develop new knowledge and shared that knowledge with those who were willing and able to learn.

Ironically, over the last decade or so we in academe have given much lip service to the concept of a student-centered learning experience. We have conducted research, designed new teaching strategies, developed new methods and materials, and published politically correct articles about the need for a learning community and putting the student at the center of the teaching/learning experience. Throughout all this discussion, however, somehow the teacher/scholar remains as the central mover or actor or core, because of our inability to escape from the ways of thinking that have been rewarded under the old paradigm.

More and more, however, I have started to come across faculty who have had the experience of a student in class citing more recent information (found on the Internet before class) than what the professor was presenting, thus making the professor appear (perhaps correctly) to be less informed than the student. Under the new paradigm we finally have what we wished for-a true student-centered learning environment. Thanks to the Internet, instant messaging, camera phones, satellite phones, and $\mathrm{CNN}$, the learner sits at the center of an information-rich environment in which the college professor is only one of many different sources of information. We may argue about the validity, reliability, and accuracy of that information, or even bring up that old chestnut about the difference between information, knowledge, and wisdom, but the point is that the teacher/scholar, or even the traditional library, is no longer the only game in town insofar as the student/learner is concerned. With this shift in the teaching/learning paradigm has come a decline in society's respect for the professoriate.

\section{The Post-Tenure Review Phenomenon}

Another element of pain being felt within the academy is the move to posttenure review. Under the old paradigm, tenured faculty were considered the core of the academy - those senior, seasoned paragons of the pedagogical priesthood-upon which the success and reputation of the institution 
depended. Tenure, originally intended to protect faculty from being punished for teaching a "truth" that contradicted church doctrine or popular societal beliefs, became, in the government-supported paradigm (and the resultant litigiously oriented society), essentially a lifetime guarantee of employment regardless of the quality of performance.

Under the new marketplace paradigm, tenured faculty are seen as an economic albatross hung around the budgetary neck of the educational institution. More and more colleges and universities are moving toward the use of part-time, adjunct, and limited-contract faculty. In fact, I have seen some institutions where more than $80 \%$ of the entire curriculum was taught by part-time or adjunct faculty. The increased use of nontenure earning faculty positions, along with the growth of the post-tenure review phenomenon would appear to signal the decline, if not the demise, of tenure. In the new, outcomes-oriented, market-driven paradigm there appears to be no place for tenure.

\section{Devaluation of the College Degree}

Under the old paradigm the amount of information available on any subject was assumed to grow very slowly. So, curricula were developed based on a fixed period of time to learn a relatively fixed amount of information. A bachelor's degree in virtually any field was expected to be completed in four years (with summers off so students could work in the fields to help plant and bring in the harvest). Under the old paradigm students taking longer than four years to complete a degree were traditionally seen as evidence of some sort of problem or failure.

In today's paradigm the amount of information in virtually every field is growing exponentially. Yet our degree programs (with a few exceptions) continue to be designed essentially as fixed-time experiences. Faculty, concerned about trying to get the latest research information into their fixed number of courses, are assigning more readings, moving more quickly through dense PowerPoint slides, and generally trying to cover more material in the time allotted-all the while agonizing over the fear that their student ratings will be lowered if they make their courses too hard. Students, on the other hand, are reporting greater stress because of the content-overloaded courses, and some are increasingly responding with the psychologically predictable response of cheating.

The academy is responding slowly by adding new layers of degrees. In some fields where a bachelor's degree was considered an appropriate entrylevel degree into a profession, it has now moved to the master's degree. In 
other areas, where a master's degree was sufficient for certification, now a doctoral degree is required. Ironically, the effect of this has been a certain devaluing of the college degree. A bachelor's degree is now often considered in the same way that a high school diploma used to be considered.

Even though certain fields have added layers of degrees to try to accommodate the knowledge explosion, within higher education we generally continue with the fixed-time-variable-learning format. We often simply push more and more information into the time allotted, easing up on our grading standards so we don't have the majority of students failing. This is especially serious in the sciences since there is a veritable tsunami of new research information coming out every year that faculty must try to fit into their coursesand students must try to learn and master. For example, in the medical school on my campus it is common to hear among both faculty and students the expression "by the time you graduate half of everything you know will be wrong." This is not so much an assessment of the quality of teaching, but simply a recognition of the exponential growth in information within the biomedical and health sciences.

Our curricular designs have persisted in the tradition of keeping time constant and letting the amount of learning vary. However, the demands of the new paradigm require that time be flexible and that the amount of learning meet a specific level. On more than one occasion I have heard a president or vice president of a college or university publicly state that they are no longer interested in equality of opportunity but, rather, equality of outcome. If a student is admitted to an institution of higher learning there is an obligation, growing pressure, for that institution to award them a degree. However, since the academy's tradition is to hold time constant and allow the amount of learning to vary, the only way it can meet this obligation is to lower the standards for degrees. We can see evidence of this in the phenomenon of grade inflation and, in some cases, the systematic reduction of the number of hours required to get a degree. All this, of course, contributes to the social devaluing of the college degree and the consequent devaluing of the entire higher education enterprise as a function society is willing to support with public monies.

\section{Emergence of Survival Learners}

The impact of technology on everyday life has had an interesting consequence on the knowledge business and has produced a whole new cadre of what might be called survival learners. That is, people who need to learn 
specific information or acquire a specific skill to get ahead in their job or even to remain employed.

When I was a young boy I had an uncle who had only a third grade education but worked as a "shade tree mechanic" repairing cars in his backyard. This work enabled him to own his own (small) house and support my aunt and cousin. The automotive technology of the time was of such a nature that it was possible for a relatively uneducated person to learn how to repair and maintain an automobile. Today's automotive technology is so complex that it requires highly specialized training to use the sophisticated computerized equipment involved in an automobile's repair and maintenance. Thus, during my lifetime the knowledge necessary to maintain the technology that moves people in a motorized carriage from point $A$ to point $B$ has grown to the point that some form of advanced education and skill is needed to maintain it. Interestingly, the same phenomenon is impacting virtually every aspect of the work world-from ditch digger to secretary to physician to college professor.

This phenomenon has resulted in a whole new spectrum of learners that might be called survival learners. That is, individuals who are not particularly interested in getting a degree but instead, have a very short time to learn a specific body of knowledge or gain a specific skill in order to simply hold on to their job. Traditionally, higher education has dealt with that relatively small percentage of the population (18-21 year olds) who had the time to spend in a diffused or semi-focused learning/maturation experience. However, with an aging populace and the impact of technology on employability, there has emerged a large body of learners which, by and large, the academy is ignoring but from which marketplace-oriented institutions (i.e., Phoenix University, DeVry Institute, etc.) are profiting. Of course, many public community and technical colleges are much more attuned to this growing segment of the learning population and are, accordingly, tapping into the resultant financial benefits. They are learning to ride the monster.

\section{Riding the Monster}

As noted earlier, Thomas Kuhn (1970) defined a paradigm shift as a "series of peaceful interludes punctuated by intellectually violent revolutions ... [where] one conceptual world view is replaced by another" (p. 10). It is clear that the academy is no longer in a "peaceful interlude" and that certain "intellectually violent revolutions" are taking place. To succeed and thrive in the new paradigm brought about by these revolutions, I offer the following list of equally revolutionary (and, I'm sure some would consider academically blasphemous) 
changes that the academy must undertake if it is to survive and thrive under the new paradigm. I do not defend these suggestions here (that is for another time) but simply offer them as the conclusions I have drawn based on the elements of the paradigm shift just described.

- Abolish the practice of hiring into significant academic administrative positions (department chair and above) those individuals whose primary accomplishment is research and the obtaining of research grants. It is important to recognize that the successful administration of a large, complex multimillion-dollar enterprise requires professional-level skills in such areas as leadership, budgeting, personnel management, conflict management, public speaking, fundraising, and policy analysis and development. The skills required to be a successful and productive researcher overlap very little with, and are sometimes antithetical to, those skills required to be a successful academic administrator.

- Within the academy organizationally separate the functions of instruction and assessment. Ideally, centers for the assessment of learning outcomes should be established as key academic support resources that provide faculty with valid, reliable, criterion-referenced measures of their students' learning and provide knowledge and skill certification services that formally confirm the competency an individual may already possess in a specific area, regardless of how or where they gained that competency.

- Within all degree programs, develop modularized curricula that are time independent but learning-outcome constant. That is, establish curricular programs through which students may proceed at their own pace to gain specific knowledge and skills required to pass an objective, criterion-referenced set of examinations. Award degrees on the basis of successful performance on such exams. Certify knowledge and competency, not seat time.

- In order to meet the accreditation demands of outcomes-based assessment, abolish the classroom practice of grading on the curve and, in its place, institute a criterion-referenced grading system. This will require, of course, that faculty become proficient in instructional systems design and instructional assessment techniques-or to make use of the appropriate instructional and assessment support services noted earlier.

- In order to attract the growing numbers of survival learners, offer curricular modules that lead to specific knowledge or skill without necessary 
reference to a particular degree. The knowledge explosion's effect on the workplace has been to make continuous learning a necessity for continued employability. Institutions offering such modules would be seen as knowledge or skill "filling stations" to which the working population would return from time to time throughout their careers in order to maintain their employability.

- Establish a differentiated faculty staffing model for colleges and universities in which faculty may be hired only to teach, or only to conduct research and write grant proposals, or only to advise students, serve as program administrators, and so on.

- Redefine the teaching professoriate as a meta-profession-a profession that is recognized as building upon, and going significantly beyond, scholarship. Start requiring individuals hired to teach to meet a higher professional standard than those hired solely to conduct research. That is, require such faculty to not only have high levels of content expertise but to also demonstrate high levels of expertise in instructional design, instructional delivery, and instructional assessment (Theall \& Arreola, 2001). Pay such individuals higher salaries than the base salaries of individuals hired solely to conduct research.

- Establish faculty evaluation/development systems that both adequately reward faculty for the performance of their specific professional duties (whether it be teaching, research, or service) and provide meaningful support designed to enable faculty to gain the knowledge and expertise needed to carry out their meta-professional responsibilities.

- Require teaching faculty to be personally responsible for the maintenance of their content expertise. Cut back on traditional faculty development programs designed to support them in their efforts to become more proficient in their content fields (the one area in which they are already most expert). Instead, institute fully supported in-house professional development programs designed to provide faculty with expertise in the metaprofessional skills of instructional design, delivery, and assessment.

- Include as a core offering within any doctoral degree program a sequence on instructional design, delivery, and assessment. Although not all individuals getting a doctoral degree will go on to become college professors, it is from such programs that college faculty come. Therefore, it is imperative that we plant the seeds of the meta-professional skills in our doctoral degree programs. 
- Abolish tenure (or at least let it die a quiet death) and replace it with a series of three-, five-, and seven-year contracts that call for the performance of specific professional duties that lead to specific, measurable outcomes.

- Stop accepting academic freedom as an excuse for instructional incompetence. The new marketplace paradigm does not encompass the concept of academic freedom. Rather, it rewards and supports those that can deliver an instructional experience that results in the learner acquiring (quickly and cost effectively) the knowledge or skill required.

These changes are simply my take on what the academy must do to survive and thrive in the new marketplace paradigm. Not everyone will agree with these suggestions. Regardless, the marketplace will continue to nourish those organizations that make the appropriate changes and simply starve out those that do not. In short, the academy must learn to ride the monster or risk being consumed by it.

\section{Note}

I am indebted to my good friend and colleague, Raymond $\mathrm{H}$. Colson, vice chancellor for administration at the University of Tennessee Health Science Center, whose expertise in economics and government funding of education has provided me with a perspective on the market forces impacting higher education that I might otherwise never have gained.

\section{References}

Arreola, R. A., Aleamoni, L. M., \& Theall, M. (2001). College teaching as meta-profession: Reconceptualizing the scholarship of teaching and learning. Paper presented at the 9th annual American Association for Higher Education Conference on Faculty Roles and Rewards, Tampa, FL.

Arreola, R. A., Theall, M., \& Aleamoni, L. M. (2003). Beyond scholarship: Recognizing the multiple roles of the professoriate. Paper presented at the 83rd annual meeting of the American Educational Research Association, Chicago, IL.

Boyer, E. L. (1990). Scholarship reconsidered: Priorities of the professoriate. Princeton, NJ: Carnegie Foundation for the Advancement of Teaching.

Burd, S. (2005, January 7). Change in federal formula means thousands may lose student aid. Chronicle of Higher Education, p. Al. 
Davis, S., \& Botkin, J. (1994). The monster under the bed: How business is mastering the opportunity of knowledge for profit. New York, NY: Simon \& Schuster.

Field, K. (2005, January 7). Pork crowds out the competition. Chronicle of Higher Education, p. A33.

Howard Hughes Medical Institute. (2004). Making the right moves: A practical guide to scientific management for postdocs and new faculty. Chevy Chase, MD: Author.

Kuhn, T. S. (1970). The structure of scientific revolutions (2nd ed.). Chicago, IL: University of Chicago Press.

Mangan, K. S. (2005, January 14). Berkeley law dean calls for partial privatization of his school. Chronicle of Higher Education, p. A25.

National Center for Higher Education Management Systems. (2000, August). The competency standards project: Another approach to accreditation review. Washington, DC: Council for Higher Education Accreditation.

Schmidt, P. (2003, December 19). Accept more state control or go private. Chronicle of Higher Education, p. A24.

Selingo, J. (2003, February 28). The disappearing state in public higher education. Chronicle of Higher Education, p. A22.

Theall, M., \& Arreola, R. A. (2001). Beyond the scholarship of teaching: Searching for a unifying metaphor for the college teaching profession. Paper presented at the 81st annual meeting of the American Educational Research Association, Seattle, WA. 